\title{
Defect structure of Czochralski silicon co-implanted with helium and hydrogen and treated at high temperature - pressure
}

\author{
W. Wierzchowski ${ }^{1}$, A. Misiuk ${ }^{2}$, K. Wieteska ${ }^{3}$, J. Bak-Misiuk ${ }^{4}$, W. Jung ${ }^{2}$, A. Shalimov ${ }^{4}$, \\ W. Graeff ${ }^{5}$, and M. Prujszczyk ${ }^{2}$ \\ ${ }^{1}$ Institute of Electronic Materials Technology, Wolczynska 133, PL-01-919 Warsaw, Poland \\ 2 Institute of Electron Technology, Al. Lotnikow 46, PL-02-668 Warsaw, Poland \\ ${ }^{3}$ Institute of Atomic Energy, PL-05-400 Otwock-Swierk, Poland \\ ${ }^{4}$ Institute of Physics, PAS, Al. Lotnikow 32/46, PL-02-668 Warsaw, Poland \\ ${ }^{5}$ HASYLAB at DESY, Notkestrasse 85, D-22603 Hamburg, Germany \\ Corresponding author: Tel. +48-22-548-7792; fax +48-22 847-0631; \\ E-mail: misiuk@ite.wawpl (A. Misiuk)
}

\begin{abstract}
Effect of stress created by Ar hydrostatic pressure (HP) up to $1.1 \mathrm{GPa}$ during annealing at the high temperature (HT) $1070 \mathrm{~K}$ (HT-HP treatment) on microstructure of Czochralski grown silicon co-implanted with helium and hydrogen $\mathrm{Si}(\mathrm{He}, \mathrm{H})$ using the same doses of $\mathrm{He}^{+}$and $\mathrm{H}_{2}^{+}\left(D_{\mathrm{H}, \mathrm{He}}=5 \cdot 10^{16} \mathrm{~cm}^{-2}\right.$, at energy 50 and $150 \mathrm{keV}$, respectively) was investigated by means of X-ray (synchrotron) diffraction, transmission electron microscopy, and electrical measurements. The nanostructured sponge-like buried layers are formed in Si:(He,H) by annealing / high pressure treatment. Decreased interference, diffuse scattering and individual contrast are observed in the synchrotron topograms for HT-HP treated Si:(He,H). The treatment at $723 \mathrm{~K}$ and HP results in an additional donor formation as a sequence of the implantation-disturbed layer. The HP-mediated (retarded) out-diffusion of hydrogen and helium is in part responsible for the effects observed.
\end{abstract}

Keywords: $\mathrm{Cz}-\mathrm{Si}$, hydrogen, helium, implantation, diffusion, high pressure, treatment.

Manuscript received 10.02.05; accepted for publication 18.05.05.

\section{Introduction}

Hydrogen implantation is used in silicon-on-insulator (SOI) technology in a smart-cut process [1]. Agarwal et al. [2] showed that the smart-cut process can be improved by helium and hydrogen co-implantation to produce $\mathrm{Si}(\mathrm{H}, \mathrm{He})$. Co-implantation of hydrogen and helium makes also possible to study an interaction of gas ions implanted into $\mathrm{Si}$ and to compare the roles of $\mathrm{H}$ and $\mathrm{He}$ in out-splitting of Si:(H,He) on annealing [3]. The smart-cut effect in $\mathrm{Si}:(\mathrm{H}, \mathrm{He})$ takes place because of the build-up of internal pressure in the buried disturbed layer containing implanted atoms which create $\mathrm{H}$, He-filled bubbles and platelets on annealing. Some new results concerning the structural phenomena during the smartcut process were published recently by Usenko et al. [4]. It was reported [3, 5-8] that enhanced hydrostatic pressure (HP) of ambient gas on annealing (HT (high temperature)-HP treatment) Czochralski silicon (Cz-Si) implanted with hydrogen and helium exerts pronounced effect on microstructure as well as on gettering processes within the implantation damaged areas. Also recently it was determined that, by changing the external (hydrostatic) pressure on annealing of Si: $(\mathrm{H}, \mathrm{He})$ and the sequence of the $\mathrm{H}$ - and He-enriched layers, it is possible to tune some properties of the $\mathrm{Si}:(\mathrm{H}, \mathrm{He})$ structures $[5,6]$.

It is well known that oxygen-related centres formed in oxygen containing $\mathrm{Cz}-\mathrm{Si}$ are responsible for thermal donor (TD) formation at about $720 \mathrm{~K}$. An application of increased HP of argon atmosphere during a heat treatment of $\mathrm{Cz}-\mathrm{Si}$ samples results in the strain-induced creation of TDs $[9,10]$. Similar effects of that treatment on hydrogen-enriched $\mathrm{Cz}-\mathrm{Si}: \mathrm{H}$ was also reported [11]. As it follows from rather preliminary data, a similar HPstimulated creation of TDs can be expected also for $\mathrm{Si}:(\mathrm{H}, \mathrm{He})$ [12].

The aim of this work is to determine the structural and electrical effects of the HT-HP treatment on defect structure of $\mathrm{Si}:(\mathrm{He}, \mathrm{H})$ with the reversed (in comparison to the previously investigated case of $\mathrm{Si}:(\mathrm{H}, \mathrm{He})[5,13])$ 
sequence of the layers enriched with helium and hydrogen $\left(R_{p \mathrm{He}}<R_{p \mathrm{H}}\right.$, where $R_{p}$ means the projected range of implanted ions).

\section{Experimental}

Boron doped (resistivity $4 \ldots 6 \mathrm{Ohm} \cdot \mathrm{cm})$ p-type (100) oriented $\mathrm{Cz}-\mathrm{Si}$ wafers with the initial interstitial oxygen concentration $c_{\mathrm{O}} \approx 6 \cdot 10^{17} \mathrm{~cm}^{-3}$ were used as initial crystals. Hydrogen, $\mathrm{H}_{2}^{+}$, and helium, $\mathrm{He}^{+}$, ions were coimplanted with the same doses $D_{\mathrm{H}, \mathrm{He}}=5 \cdot 10^{16} \mathrm{~cm}^{-2}$ at $T_{i} \leq 350 \mathrm{~K}, \mathrm{He}^{+}$were implanted into $\mathrm{Cz}$-Si wafers at energy $E_{\mathrm{He}}=50 \mathrm{keV}\left(R_{\mathrm{pHe}} \approx 420 \mathrm{~nm}\right)$, and $\mathrm{H}_{2}^{+}$at $E_{\mathrm{H}}=135 \mathrm{keV}\left(R_{p \mathrm{H}} \approx 580 \mathrm{~nm}\right)$. In what follows, the samples with $R_{p \mathrm{He}}<R_{p \mathrm{H}}$ are referred to as $\mathrm{Si}(\mathrm{He}, \mathrm{H})$.

The $\mathrm{Si}:(\mathrm{He}, \mathrm{H})$ samples were annealed/HT-HP treated at the temperatures up to $1070 \mathrm{~K}$ in argon atmosphere under the hydrostatic pressure up to $1.1 \mathrm{GPa}$ for $10 \mathrm{~h}$. The samples were studied using X-ray diffraction methods, transmission electron microscopy (TEM), and electrical measurements. The sample structure was checked by TEM.

The X-ray measurements were performed using $\mathrm{X}$-ray high resolution diffractometry (HRXRD) and synchrotron methods. In the HRXRD measurements we used Philips X'Pert equipment in symmetrical 004 reflection of $\mathrm{Cu} K_{\alpha 1}$ radiation.

The synchrotron investigations at the monochromatic beam station E2 in HASYLAB included taking the rocking curves using 400 symmetrical and 511 asymmetrical reflections for $0.117 \mathrm{~nm}$ radiation with a beam limited to the sizes $50 \times 100 \mu \mathrm{m}^{2}$ and the monochromatic beam topograms.

Electrical properties of the as-implanted and annealed/treated $\mathrm{Si}:(\mathrm{He}, \mathrm{H})$ samples were studied by the measurements and numerical analysis of current-voltage (I-V) and capacitance-voltage (C-V) characteristics of the Schottky barrier junction $\mathrm{Hg}$-Si (mercury probe). The measurement system was controlled via GPIB bus by PC with TestPoint environment and consisted of QuadTech 7600 admittance meter and Keithley 237 and 238 source measurements units. The QuadTech 7600 Precision LCR meter can measure the capacitance in a wide band of test signal frequencies from $10 \mathrm{~Hz}$ to $2 \mathrm{MHz}$. Keithley 237 and 238 source measurement units provided bias voltage during measurements of the I-V and $\mathrm{C}-\mathrm{V}$ characteristics. Electrical measurements of $\mathrm{Si}:(\mathrm{He}, \mathrm{H})$ samples were performed both on the top (implanted) surface and on the back (non-implanted) one.

The carrier concentration profiles were calculated from $\mathrm{C}-\mathrm{V}$ characteristics of the Schottky $\mathrm{Hg}-\mathrm{Si}$ barrier measured for test signal frequencies $1 \mathrm{kHz}$ and $1 \mathrm{MHz}$.

\section{Results and discussion}

As may be followed from Figs 1a, b, the rocking curves of as-implanted samples revealed a tail of irregular interferential peaks in the low-angle side of the peak originating from the substrate with an increased periodicity towards lower angles. These fringes are caused by a peak of the strain profiles and formed only in the samples with a small defect concentration.

The HT-HP treatment results in formation of strained buried nanostructured layers composed of partially amorphous silicon (a-Si) containing hydrogen/helium filled cavities/platelets and numerous point and extended defects.

For the treated/annealed samples, an effect of defect agglomeration leads to the fast vanishing the interferential peaks in the rocking curves and to increased X-ray diffuse scattering. In this case, it was possible to detect the formation of gaseous inclusions by means of X-ray topography. The representative pictures of gaseous inclusions obtained by synchrotron planewave topography are shown in Fig. 2.

The samples annealed under atmospheric pressure $\left(10^{5} \mathrm{~Pa}\right)$ provided some point-like contrast that is more dense for the samples annealed at $723 \mathrm{~K}$. Contrasts became less dense but more distinct for the samples treated at higher temperatures. In this case, we observe also some individual larger round-shaped contrasts. This contrast may be most probably attributed to larger gaseous inclusion or small bubbles connected with a local exfoliation. The samples become relatively flat. The samples annealed under HP $1.1 \mathrm{GPa}$ do not reveal any individual resolved contrast similarly to the asimplanted samples and those significantly bent. Also, a small part of diffuse scattering is detectable in the tails of rocking curves, but the diffuse scattering can be much better followed in the reciprocal space maps (XRRSM's) obtained using a high resolution diffractometer. No significant increase in the full width at half maximum (FWHM) was observed in the synchrotron rocking curves shown in Fig. 1, which were recorded using a very narrow probe beam.

As seen in Fig. 3a, the level of diffuse scattering is low for the as-implanted sample, and we may observe a tail along the reciprocal lattice vector, corresponding to the interferential peaks in the rocking curves in Figs 1a, b. This tail vanished in the curves of the annealed/treated samples. The treatments of $\mathrm{Si}(\mathrm{He}, \mathrm{H})$ at $723 \mathrm{~K}-\mathrm{HP}$ for $1 \ldots 10 \mathrm{~h}$ resulted in the gradually worsened (with HP) structural perfection, as evidenced by the enhanced $\mathrm{X}$ ray diffuse scattering intensity (Figs $3 \mathrm{~b}, \mathrm{c}$ ).

Electrical measurements of $\mathrm{Si}(\mathrm{He}, \mathrm{H})$ with underlaying sponge-like layer as well as of the sample back sides are tabulated in Table for the samples as-implanted and annealed/treated at $723 \mathrm{~K}$. As detected from I-V and $\mathrm{C}-\mathrm{V}$ characteristics of the Schottky barrier for $\mathrm{Si}:(\mathrm{He}, \mathrm{H})$ samples, the type of conductivity in the surface layer of the as-implanted sample was changed from the initial $p$-type (still detected on the sample back side) to the $n$-type. Because the helium projected range is smaller than that of hydrogen, one can assume that the helium implantation results in the increased generation of donor-like defect centres even for the low initial oxygen concentration in $\mathrm{Cz}-\mathrm{Si}\left(c_{\mathrm{O}} \approx 6 \cdot 10^{17} \mathrm{~cm}^{-3}\right)$. 

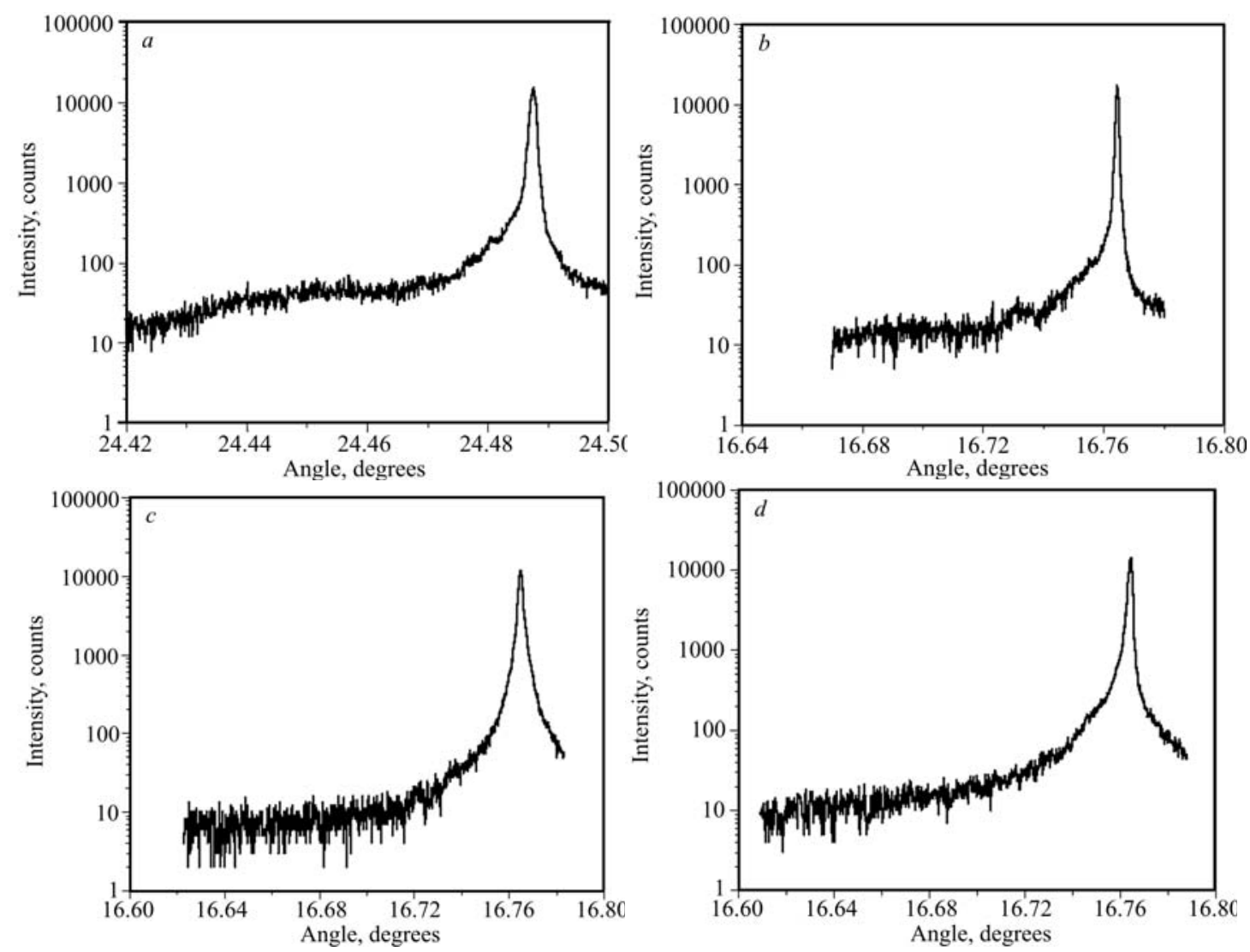

Fig. 1. Synchrotron rocking curves of $\mathrm{Cz}-\mathrm{Si}:(\mathrm{He}, \mathrm{H}): a, b$ - as-implanted, for asymmetric 400 and 511 reflections, $c$ - annealed for $1 \mathrm{~h}, 10^{5} \mathrm{~Pa}, 723 \mathrm{~K}, d$ - treated for $6 \mathrm{~h}, 1.1 \mathrm{GPa}, 723 \mathrm{~K}$.
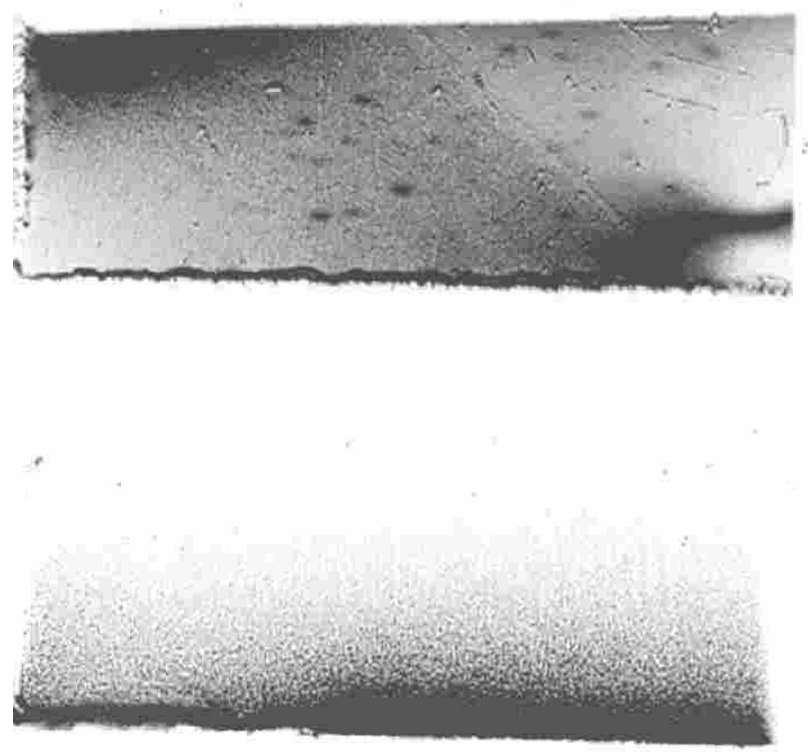

Fig. 2. 004 X-ray plane wave topograms for $\mathrm{Si}:(\mathrm{He}, \mathrm{H})$ samples: $a$ - annealed at $723 \mathrm{~K}, 10^{5}$ Pa for $1 \mathrm{~h}$, and $b$ - treated at $923 \mathrm{~K}, 1.1 \mathrm{GPa}$ for $1 \mathrm{~h}$.

The calculations of the carrier concentration for the $\mathrm{Si}:(\mathrm{He}, \mathrm{H})$ sample result that the concentration of donorlike defects is rather high (about $2 \cdot 10^{17} \mathrm{~cm}^{-3}$ ) for the as-implanted sample and decreases to the level of
$3 \cdot 10^{16} \mathrm{~cm}^{-3}$ after sample annealing at $723 \mathrm{~K}$ for $10 \mathrm{~h}$ under the atmospheric pressure. This fact means that some implantation induced donor defects, not related to the presence of oxygen, are annihilated on annealing.

The $\mathrm{H}_{2} / \mathrm{He}$ filled bubbles are detectable by TEM in the $\mathrm{Si}:(\mathrm{He}, \mathrm{H})$ samples annealed/treated in a wide temperature range [14]. TEM image of $\mathrm{Si}(\mathrm{He}, \mathrm{H})$ treated at $923 \mathrm{~K}-1.1 \mathrm{GPa}$ for $1 \mathrm{~h}$ is presented in Fig. 4. The presence of similar $\mathrm{H}_{2}$ filled cavities and bubbles was obtained also for the HT-HP treated Si:H samples [3].

As it follows from XRRSM's of the Si:(He,H) samples annealed/treated at $923 \mathrm{~K}$ (Fig. 5), no marked effect of HP on the resulting sample microstructure is detectable by this X-ray method.
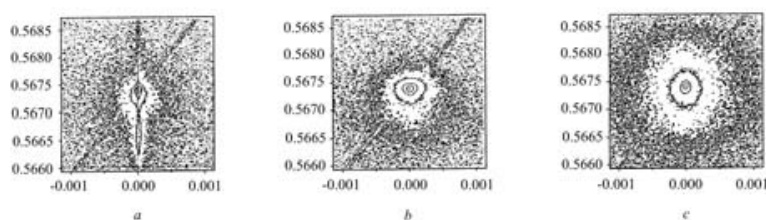

Fig. 3. XRRSM's recorded near 004 reciprocal lattice point for $\mathrm{Si}:(\mathrm{He}, \mathrm{H})$ samples, as-implanted (a) and annealed/treated for $1 \mathrm{~h}$ at $723 \mathrm{~K}$ under $10^{5} \mathrm{~Pa}(\mathrm{~b}), 1.1 \mathrm{GPa}(\mathrm{c})$, and for $10 \mathrm{~h}$ at $723 \mathrm{~K}$ under $1.1 \mathrm{GPa}(\mathrm{d})$. Axes are marked in $\lambda / 2 d$ units $(\lambda$ is the wavelength, $d$ is the distance between crystallographic planes). 


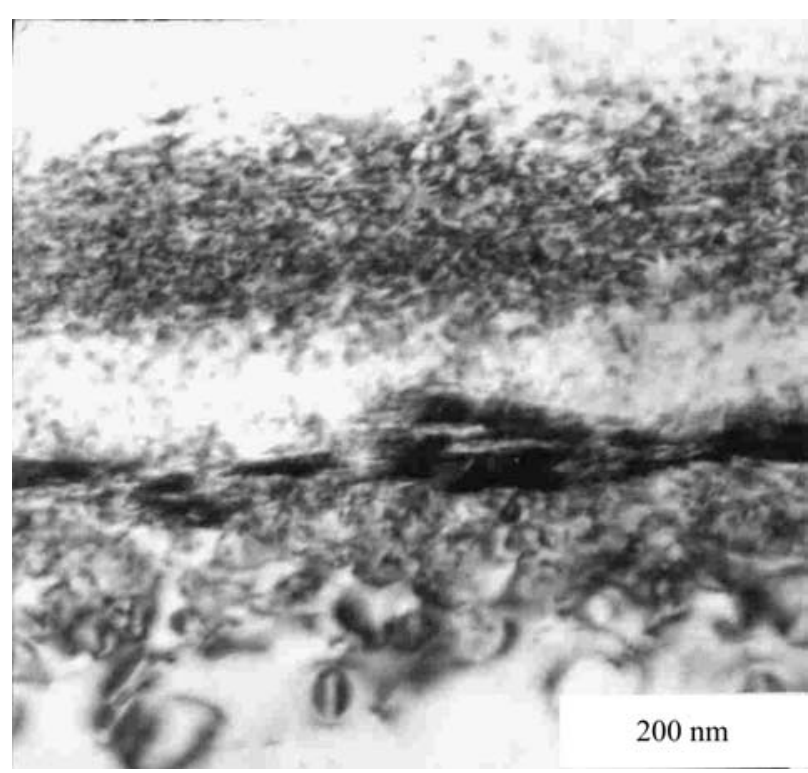

Fig. 4. XTEM image of $\mathrm{Si}:(\mathrm{He}, \mathrm{H})$ sample treated for $1 \mathrm{~h}$ at $923 \mathrm{~K}$ under $1.1 \mathrm{GPa}$.

Annealing $\mathrm{Si}:(\mathrm{He}, \mathrm{H})$ at $923 \mathrm{~K}$ for $10 \mathrm{~h}$ under atmospheric pressure results in annihilating all donor centres not related to the presence of oxygen, and the surface layer recovers its initial $p$-type of conductivity, but with a much higher level of the hole concentration which means that the acceptor-like defect centres are also generated during the implantation process (Table). The concentration of these defects is increased after the heat treatment at $923 \mathrm{~K}$ under $1.1 \mathrm{GPa}$ for $10 \mathrm{~h}$.

We have observed that the application of an increased hydrostatic pressure of argon atmosphere during the heat treatment of $\mathrm{Si}:(\mathrm{He}, \mathrm{H})$ resulted in rather small stress-induced creation of TDs because of the low oxygen concentration. It is particularly evident for the sample back side as shown in Table.

The XRRSM data of the $\mathrm{Si}:(\mathrm{He}, \mathrm{H})$ samples treated at $1070 \mathrm{~K}$ are indicative of some improvement of their crystallographic perfection with increasing HP manifested by smaller diffuse scattering (Fig. 6).

Our investigations concerned $\mathrm{Cz}-\mathrm{Si} \mathrm{Si}:(\mathrm{He}, \mathrm{H})$ samples: prepared by sequential helium and hydrogen implantation at $T \leq 370 \mathrm{~K}$ with the same $\mathrm{H}$ and $\mathrm{He}$

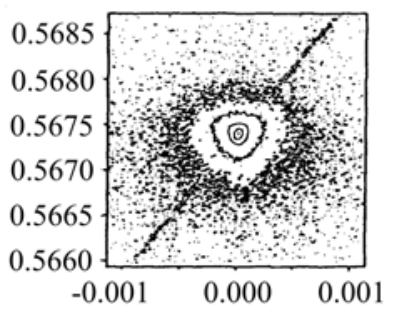

a

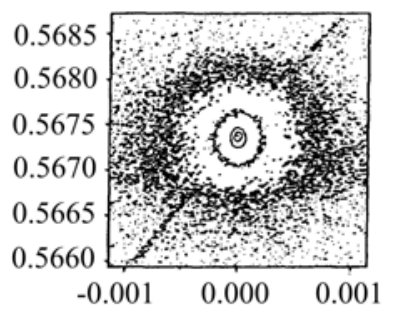

$b$
Fig. 5. XRRSM's recorded near 004 reciprocal lattice point for $\mathrm{Si}:(\mathrm{He}, \mathrm{H})$ samples, annealed/treated for $1 \mathrm{~h}$ at $923 \mathrm{~K}$ under $10^{5}$ $\mathrm{Pa}$ (a) and $1.1 \mathrm{GPa}(\mathrm{b})$. Axes are marked as in Fig. 3.
Table 1. Carrier concentration and conductivity type of $\mathrm{Si}(\mathrm{He}, \mathrm{H})$ samples. Electrical measurements were performed on the sample surface taking into account the existence of buried sponge-like layer as well as the sample back contact.

\begin{tabular}{|l|l|l|}
\hline \multirow{2}{*}{ Samples Si:(He,H) } & \multicolumn{2}{|c|}{$\begin{array}{r}\text { Carrier concentration }\left[\mathrm{cm}^{-3}\right], \\
\text { type of conductivity }\end{array}$} \\
\cline { 2 - 3 } & Implanted side & \multicolumn{1}{|c|}{ Back side } \\
\hline 1. As-implanted & $2 \cdot 10^{17}, n$ & $1 \cdot 10^{15}, p$ \\
\hline $2.723 \mathrm{~K}, 10^{5} \mathrm{~Pa}, 1 \mathrm{~h}$ & $1 \cdot 10^{17}, n$ & $1 \cdot 10^{15}, p$ \\
\hline $3.723 \mathrm{~K}, 0.1 \mathrm{GPa}, 1 \mathrm{~h}$ & $1.7 \cdot 10^{17}, n$ & $1 \cdot 10^{15}, p$ \\
\hline $4.723 \mathrm{~K}, 0.6 \mathrm{GPa}, 1 \mathrm{~h}$ & $2 \cdot 10^{17}, n$ & $1 \cdot 10^{15}, p$ \\
\hline $5.723 \mathrm{~K}, 1.1 \mathrm{GPa}, 1 \mathrm{~h}$ & $1.5 \cdot 10^{17}, n$ & $1 \cdot 10^{15}, p$ \\
\hline $6.723 \mathrm{~K}, 10^{5} \mathrm{~Pa}, 10 \mathrm{~h}$ & $3 \cdot 10^{16}, n$ & $1 \cdot 10^{15}, p$ \\
\hline $7.723 \mathrm{~K}, 1.1 \mathrm{GPa}, 10 \mathrm{~h}$ & $1 \cdot 10^{17}, n$ & $1 \cdot 10^{15}, p$ \\
\hline $8.923 \mathrm{~K}, 10^{5} \mathrm{~Pa}, 10 \mathrm{~h}$ & $6 \cdot 10^{16}, p$ & $1 \cdot 10^{15}, p$ \\
\hline $9.920 \mathrm{~K}, 1.1 \mathrm{GPa}, 10 \mathrm{~h}$ & $8 \cdot 10^{16}, p$ & $1 \cdot 10^{15}, p$ \\
\hline
\end{tabular}

doses $\left(D=5 \cdot 10^{16} \mathrm{~cm}^{-2}\right)$ and with maximum He concentrations lower in respect to that of hydrogen $\left(R_{p \mathrm{H}} \approx\right.$ $580 \mathrm{~nm})$. The $\mathrm{H}$ - and He-containing areas were almost overlapping owing to extended tails of the distributions of the implanted species. The presently discussed X-ray and electric measurements correspond with the photoluminescence (PL) and SIMS measurements in similar samples [5, 13]. Some specific HT-HP induced phenomena were determined, among them:

- the increased hydrogen out-diffusion and so the lowered $\mathrm{H}$ concentration in the samples treated at HT (1...1.1) GPa, in comparison to those treated under the lower pressures $10^{5} \ldots 10^{7} \mathrm{~Pa}$.

- HP-mediated suppression of oxygen accumulation, especially at $720 \mathrm{~K}$, and general improvement with $\mathrm{HP}$ of the crystallographic perfection of $\mathrm{Cz}-\mathrm{Si}:(\mathrm{H}, \mathrm{He})$ and Cz-Si:(He,H) samples.

The first mentioned effect is unexpected, and, as it concerns our knowledge, the first of this kind reported. The lowered hydrogen concentration in $\mathrm{Cz}-\mathrm{Si}:(\mathrm{He}, \mathrm{H})$ samples treated at the temperature up to (at least) $1070 \mathrm{~K}$ under HP up to (at least) $1.1 \mathrm{GPa}$ is evidently related to
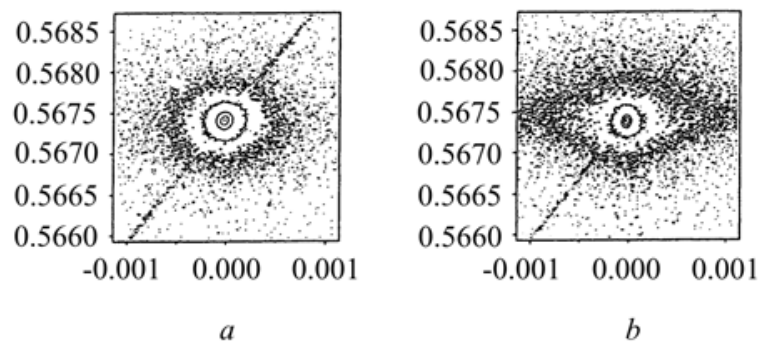

Fig. 6. XRRSM's recorded near 004 reciprocal lattice point for $\mathrm{Si}:(\mathrm{He}, \mathrm{H})$ samples, treated for $5 \mathrm{~h}$ at $1070 \mathrm{~K}$ under $10^{5} \mathrm{~Pa}$ (a) and $1.1 \mathrm{GPa}(\mathrm{b})$. Axes are marked as in Fig. 3. 
the more rapid hydrogen out-diffusion from $\mathrm{Cz}$ Si:(H,He) at $720 \ldots 1070 \mathrm{~K}$ and so to the HP-mediated enhancement of the effective hydrogen atom mobility.

No unique explanation of the lowered hydrogen storage in silicon co-implanted with helium and hydrogen can be given at present. It is obvious that the considered phenomenon is related to the presence of $\mathrm{He}$ (or to creation of some specific He-induced defects), because implantation of the only hydrogen leads to a much more obvious effect of the enhanced hydrogen concentration in HT-HP treated Si:H. The effect seems to be related to the influence of $\mathrm{He}$ atoms on the behaviour of hydrogen in silicon - most probably the He-filled microcavities/bubbles in $\mathrm{Si}:(\mathrm{H}, \mathrm{He})$ affects creation of the $\mathrm{H}-\mathrm{Si}$ bonds. It was reported in [14] that, after filling, the vacancy-like defect created at implantation and at the beginning of annealing/treatment step, some hydrogen molecules in $\mathrm{Si}: \mathrm{H}$ react with dangling or strained $\mathrm{Si}-\mathrm{Si}$ bonds creating $\mathrm{Si}-\mathrm{H}$ silanic terminations. Under atmospheric pressure hydrogen out-diffuses appreciably from Si:H at $T \geq 720 \mathrm{~K}$. The lowered hydrogen outdiffusion rate was obtained for $\mathrm{Si}(\mathrm{H}, \mathrm{He})$ annealed at $570 \ldots 720 \mathrm{~K}$ [14]. It was explained by the He presence, owing to the increased number of $\mathrm{H}-\mathrm{Si}$ bonds.

In the case of $\mathrm{Si}(\mathrm{He}, \mathrm{H})$, with $R_{p \mathrm{H}}>R_{p \mathrm{He}}$ at $\mathrm{HT}$ hydrogen, out-diffuses from the sample reaching the originally He-filled cavities and bubbles. Probably, also some (not so numerous) He atoms would reach the originally $\mathrm{H}$-filled cavities and bubbles in the vicinity of $R_{p \mathrm{H}}\left(>R_{p \mathrm{He}}\right)$ by the in-sample diffusion. Consequently, part of hydrogen would become immobilized in those cavities and bubbles (in respect of its further diffusion) because of creation of the mentioned $\mathrm{H}-\mathrm{Si}$ bonds.

The observed effect of enhanced hydrostatic pressure during annealing on the suppression of oxygen accumulation/gettering and on the creation/annihilation of crystallographic defects [13] is related to decreased diffusivity of oxygen interstitials during HP. The oxygen accumulation in $\mathrm{Cz}-\mathrm{Si}:(\mathrm{H}, \mathrm{He})$ is affected also by the above discussed indirect interaction between hydrogen and helium difficult for understanding at the present stage of investigations. Explanation of other observed structural transformations during HT-HP is even more difficult, and so further investigation is also needed to solve this problem.

\section{Conclusions}

Using the rocking curves and XRRSM's of Cz$\mathrm{Si}:(\mathrm{He}, \mathrm{H})$, we revealed characteristic interferential peaks with increased periodicity on low-angle side of the substrate related peak, which may be attributed to strains reaching their maximum under the surface. After annealing and the HT-HP treatment, the interferential effects vanish, and the increased X-ray diffuse scattering was observed; still some individual contrast was recognizable by the monochromatic beam topography, which may be caused by formation of larger gaseous inclusions. A certain improvement of the structure was observed in case of HT-HP treatment performed for the highest values of the temperature and pressure.
Formation of the sponge-like layers in $\mathrm{Cz}-\mathrm{Si}$ exposed to implantation with helium and oxygen and to high temperature-pressure treatment is accompanied with the creation of the structural and electrically active defects such as oxygen related TDs both donor-like and acceptor-like. Electrical properties of sponge-like silicon surface structures formed by the high pressure annealing of silicon co-implanted with hydrogen and helium are dependent on the implantation and treatment conditions. There was determined the possibility to form the $p-n$ junctions with various carrier concentration levels influencing on the semiconductor device properties by changing the projected range of implanted ions and the conditions of the high temperature-pressure treatment.

\section{Acknowledgements}

The authors are grateful to Dr J. Ratajczak (Institute of Electron Technology, Warsaw) for some TEM data.

\section{References}

1. M. Bruel // Electron. Lett. 31, p.1201 (1995).

2. A. Agarwal, T.E. Haynes, V.C. Venezia, O.W. Holland, D.J. Eagleshman // Appl. Phys. Lett. 72, p. 1086 (1998).

3. A. Misiuk, J. Bak-Misiuk, M. Kaniewska, K.S. Zhuravlev, V. Raineri, I. V. Antonova // Mater. Phys. Mech. 5, p. 31 (2002).

4. A. Usenko, W. Carr B. Chen // Proc. of $14^{\text {th }}$ Int. Conf. on Ion Implantation Technology, IIT 2002, September 22-27, 2002, Taos, New Mexico, USA.

5. A. Misiuk, A. Barcz, J. Ratajczak, J. Bak-Misiuk // Solid State Phen. 95-96, p. 313 (2004).

6. A. Misiuk // Mater. Phys. Mech. 1, p. 119 (2000).

7. A. Misiuk, J. Bak-Misiuk, I.V. Antonova, V. Raineri, A. Romano-Rodriguez, A. Bachrouri, H.B. Surma, J. Ratajczak, J. Katcki, J. Adamczewska, E.P. Neustroev // Comput. Mater. Sci. 21, p. 515 (2001).

8. A. Misiuk, A. Barcz, V. Raineri, J. Ratajczak, J. Bak-Misiuk, I.V. Antonova, W. Wierzchowski, K. Wieteska // Physica B 308-310, p. 317 (2001).

9. A. Misiuk, W. Jung // Phys. status solidi (b) 198, p. 565 (1996).

10. V.V. Emtsev, B.A. Andreev, A. Misiuk, W. Jung, K. Schmalz // Appl. Phys. Lett. 71, p. 264 (1997).

11. A. Misiuk, J. Ratajczak, B. Surma, A.G. Ulyashin, A. Barcz, W. Jung, // J. Phys. Condens. Matter 15, p. $7445(2003)$

12. W. Jung, A. Misiuk, J. Ratajczak // Mater. PSST 2004 Conference (Cullera Valencia, 2004), p. 248 (2004).

13. A. Misiuk, J. Ratajczak, A. Barcz, J. Bak-Misiuk, A. Shalimov, B. Surma, A. Wnuk, J. Jagielski, I.V. Antonova, in: T.N. Veziroglu et al. (eds), Hydrogen Materials Science and Chemistry of Carbon Nanomaterials, Kluwer Academic Publishers. Printed in the Netherlands, pp. $579-592$ (2004).

14. G.F. Cerofolini, G. Calzolari, F. Corni, C. Nobili, G. Ottaviani, R. Tonini // Mater. Sci. Eng. B71, p. $96(2000)$. 